\title{
The Effect of Management Support on the Delivery of Devolved Services in Selected Counties in Kenya
}

\author{
Fauziya Brek Karama, PhD Student \\ Department of Entrepreneurship, Technology, Leadership and Management, \\ College of Human Resource Development, Jomo Kenyatta University of \\ Agriculture and Technology, Kenya \\ Dr. Kavoo Linge, \\ Institute of Primate research - WHO affiliated, Kenya
}

Doi:10.19044/esj.2019.v15n25p308 URL:http://dx.doi.org/10.19044/esj.2019.v15n25p308

\begin{abstract}
Devolution is a tool that brings government services closer to the people. Several countries are devolving functions so as to improve service delivery, enhance governance, accountability and increase equity. Kenya embarked on an ambitious devolution program which has achieved marked degrees of success. Thus, this paper investigated effect of the management support on the delivery of devolved services in selected counties in Kenya. The study adopted a correlational analytic method targeting a population of 35,444 staff from 8 counties. A set of questionnaires were used that comprised of a population of 384 employees selected from eight counties. Structured and open-ended questionnaires were used in the study. Data analysis was done using descriptive statistics, correlation and regression analysis. Hypothesis $\mathbf{1}\left(\mathbf{H}_{\mathbf{0 1}}\right)$ stated that management support does not have a significant effect on the delivery of devolved services in selected counties in Kenya. Findings showed that management support had coefficients of estimate which was significant basing on $\beta_{1}=0.761$ ( $p$-value $=0.000$ which is less than $\alpha=$ 0.05). The null hypothesis was thus rejected and it was concluded that management support had a significant effect on service delivery The study concludes that there is need for enhanced management support and supervision to the counties during project implementation because management support provides an enabling environment at the county level that facilitates effective devolved service delivery.
\end{abstract}

Keywords: Management Support, County, Government, Devolution, Devolved Service Delivery 


\section{Introduction}

Devolution could be viewed administratively as a method of which governments give quality expansion of self-rule, decreases focal regulatory controls and improves responsiveness, receptiveness and rivalry (Sarkar, 2003). This is done by empowering the key players such as the relevant society, the private sector and engaging local residents through their upgraded interest in basic leadership. Ahmed (2005), observed that the administration of service delivery need solid connections and responsibility between the performing artists in the devolved service delivery industry. The service delivery of open administrations include responsibility where clients as residents need to consider approaching government officials responsible for allotting assets towards these administrations. In Africa Ekpo (2008) presumed that, decentralization has turned into a hypothesis of guaranteeing great administration and compelling devolved service delivery in most developing nations. However, for decentralization to succeed it needs the certainty and duty of local governments by setting up the correct arrangement and fitting institutional structure.

Service delivery is the primary hardware for county and the national government using various approaches and choices. It is the duty of the government to convey speedy, effective and quality administrations to its citizens at moderate costs. Devolved service delivery is the most imperative column for government as it's along these lines that are essential to resident organization in basic leadership in government and has constrained governments wherever to try to expand the nature of taxpayer supported organizations when the accessible assets for conveying administrations have declined (Olowu 2008).

There are success stories from across the globe on devolution and its benefits to the political stability and development such as the US, many European countries, India and some African countries (Omari, Kaburi, \& Sewe 2012). In India devolution took on a more holistic approach that encompassed both the governance structures and its processes. This approach was driven by the need to protect shifts of power paradigms and resource management from possible political interference. It was further found out that total transfer of powers and responsibilities to the grassroots contributed significantly to India's health devolution successful experiment.

Devolution is not always a success story like in the Philippines and Latin America, there were significant failures of this system of government to an extend that some developed functions such as the health sector were severely compromised. This was found majorly to be due to failure to identify correctly the determinants of devolution among the various devolved sectors (Woong \& Yaccob, 2007). 
Devolution in Africa ensures good governance and effective service delivery however, for devolution to succeed, there must be adequate frameworks to regulate the relationship between the national government, the counties and the devolved units so that no roles and responsibilities are neglected or duplicated (Expo, 2007). Mchrorta (2006) established that there does exists a clear and significant relationship between effectiveness of service delivery and overall improvement of health sector. It was found that devolution in primary healthcare decision-making improved the quality, availability and reliability of essential medical services significantly such as immunizations that resulted in significant reduction in infant mortality and morbidity among some West African states and Mozambique. Olowu and Wunsch (2004) and Majekodunmi (2012 working in Nigeria observed similar findings and concluded that due to diminished capacity of the public sector, the primary role of devolution is to build up capacity and knowledge in its human resource base. There is therefore, need to expressly conceptualize clear action plans and come up with policies and frameworks that encourage more knowledge acquisition and exchange that ultimately will improve efficiency in service delivery.

In Botswana, Sharma (2010) found that devolved units have to ensure proper management of public funds if they are to encourage public trust and participation. Lapses in funds control and diligence result in pilferage and corruption that erode public trust and reduces their level of participation because of the disillusionment that it creates.

Various district different historical dispensations of devolution in different counties were reported by Jumal, Rotich and Mulongo (2014) as follows:- In South Africa, post-apartheid devolution took on a social approach that sought to rehabilitate personal relationships among the diverse public that sought to rebuild their social fabric. According to Bigambo (2013), the post genocide Rwanda devolution took on an economic rejuvenation approach that aimed to bring about reconciliation and social change by empowering people to increase their household incomes through trade and a robust economy. In Uganda, devolution sought to empower people at the basic governance unit and the local councils because of the large number of people at the grassroots that felt neglected by the central government (Kauzya (2007). In Tanzania, devolving responsibilities and powers led to increased availability of quality services that promoted public goodwill through active participation (Lufunyo, 2014).

In the understanding of devolution, Adek (2016) noted that the various project implementations in the devolved Governments have been the only way of bringing activities that serve the people positively leading to better coexistence in the society. These projects are diverse and include infrastructural, educational, mining, water, small and medium enterprise projects and general 
industrialization among the services that every county government whether newly established or old is expected to perform. On the other hand, these services can only be realized if determinants such as county government legislative processes would improve their ability and capacity to leverage their revenue collections and management of funding by both the central government and devolved government so as to drive local development. Availability of the resources is also another key determinant. Without attention to these determinants, devolution will still remain a blue print in many African countries that are now in the process of devolution implementation.

Ayuso (2011) took special note of the county leaders' accountability that were of great influence on services delivered as they were not accessible to citizens as expected among several counties in Kenya.The study also found that financial rate of flow, timely transfers and citizen participation in meetings greatly influenced county service delivery. As such, understanding the determinants of service delivery, as this determines the implementation of devolved system of government services. This will avoid the negative effects and straighten the way forward towards implementation of key functions. Hence a study as the present one will be strategic so as to un-earth what impairs successful devolution in Kenya. The few studies done locally (Wagana, 2014) were not exhaustive in investigating the effect of governance decentralization on service delivery. The study done by Savange and Lumbasi, (2016) suffered conceptual gaps since it concentrated on two counties only and covered education and health sector while the focus of the current study is on eight counties. This study aims to explore the gaps in previous studies on effect of management support on the delivery of devolved services in selected counties in Kenya.

\section{Hypothesis development}

Management support is a prerequisite for effective and quality service delivery because it sets the tone for the standardization of products and services (Lodorfos, 2015). Therefore, management support will shape organizations and provides enabling environment for effective devolved service delivery. As such, for any organization to effectively make changes in its structures, systems and processes, it has to ensure that all its top management are for the change because of the trickle-down effect top management endorsement has (Heathfield, 2018). Most organizations face challenges and problems in their implementation of changes because of resistance from their decision makers that reduces its uptake down the rank and file and in most cases disgruntlement among top management results in the rejection of changes. 
Devolved system leadership should develop a clear vision of the expectations of the new system and how they expect to reach the desired goals if they are to influence a strong following of their staff and public. It is especially important that the vision development takes on a dimension that is greater than that of either the leaders or the public and not just what the latter want to hear. Developing a vision that transcends the short-term expectations and challenges in society gives counties more bandwidth to innovate changes and improvements that should improve the quality of life of their people significantly and sustainably. In addition, it provides it with considerable opportunities for knowledge development that improve the ownership of the resulting new systems and interventions (Heathfield, 2018).

Thus, this study hypothesized that:

-Management support does not have a significant effect on the delivery of devolved services in selected counties in Kenya.

\section{Empirical Review}

Every government is faced with the challenges of citizenry satisfaction, which require the application of relevant management principles so as to remain relevant. The need for service delivery appears to have been appreciated. However, the county governments have experienced some problems in delivering devolved services. Some of the devolved services include; public service administration, agriculture, culture and sports, housing, urban development and physical planning, Education, Transport and Public works, Health, Treasury, Environment and water, Trade, Industrialization and Tourism departments. This means that in their provision of services, they satisfy the needs and remain subject to the control, direction and influence of the locals (Oloo, 2012).

Kisumu County Government became the first county to sign publicly, performance contracts in August 2014. Signing the contract signified the county's commitment to ensuring service delivery. The signing of the contracts was preceded by support from UNDP and training by the Ministry of Devolution and Planning of 54 Senior County Government Officials. Thus was aimed at equipping them with knowledge, skills on change, performance management, monitoring and evaluating results. During the training, the Governor called on these officers to be committed and to embrace a performance management culture as a mechanism to unlock service delivery bottlenecks that the County was experiencing. Commitment to institutionalize a performance culture, through training of the officers and putting in place tools and systems to monitor performance for greater accountability at all levels was emphasized(UNDP, 2010).

Over the years, management of institutions play a vertical role in the success of service delivery. For better service delivery, there must be an 
outstanding management that provide support to its employees. For instance in 1996 South African Constitution mandated that service delivery must be oriented towards meeting the development challenges confronting South Africa, (Sing, 2012). He suggested that for a successful devolved system of government support, the following was suggested: - the importance of senior management support; the need for employees to be able to access expert advice when required; the advantages of employing personnel with the requisite interpersonal skills, equipped with relevant subject matters, project management skills; and the necessity for contract managers to be fully cognizant of contractor capabilities.

It known that every government is a very labor intensive enterprise. Public organizations provide services, enforce laws, regulations, solve problems and have varied missions. Their divergent missions include protection of the environment, food safety, elderly care, disabled assistance, education of our children and civil rights enforcement. All of these activities require the use of human resources. The quality of employees in the county directly relates to how well the county performs. Essential tasks of human resource managers are to find qualified employees for these government positions, as well as to promote an attractive work environment for these employees. Failure to use effective human resource management risks low productivity and a lack of commitment to the community. County managers have the challenge of meeting multiple objectives including productivity, staffing and service delivery, (Huntley \& Kleiner, 2014).

A study to establish the effect of management support on performance of commercial and financial State corporations in Kenya, showed that balanced organizational controls that include effective managed corporate resource portfolio, effective organizational culture with good ethical practices and balanced organizational controls, Had a positive strong relationship with annual employee turnover (Katee, 2013). These practices have been found to positively correlate highly with customer satisfaction, return on investment, net profit margin, low annual employee turnover and overall performance of an organization (Katee, 2013).

Chebet (2015) sought to determine factors that influence performance of the employees in County Governments in Kenya using a study of Bungoma County. Her Findings from the study confirmed that a significant association exists between compensation / remuneration, management support, employee training, employee development, working conditions and improved employee performance. There is therefore need for the organization to improve on training and leadership in order to achieve continued improvement. The study recommended that County governments need to develop, implement focused training development programs that embrace good management that support 
employees and also motivate them through attractive remuneration/ compensation and favorable working conditions so as to realize improved organizational performance.

Marks and Prints (2013) identified poor management as a major reason for low morale and unsatisfactory employee performance. Organizations are usually tempted to promote employees' to management and leadership roles without assessing their readiness to these roles and neglecting the need for sufficient orientation and training. When making decisions to choose managers it is worth noting that although one might be a stellar performer in his or her area of expertise they may not automatically possess the skills, knowledge and abilities to perform at the same level as managers and leaders. This means for organizations to succeed in selecting the right managers they have to take time to use evaluation tools such as behavioral interviews and psychological assessments to identify the right managers.

Relations between managers and employees have a significant effect on productivity as bad relations often lead to violations of psychological contracts, low levels of fulfillment of perceived promises and commitments made by the organization. Quality supervision requires one to have good management qualities and be in tune with their people. County leaders are expected to take charge effectively of the teams that they lead. It is also important for them to boost performance by watching over their people's backs and making their working environs conducive for them to learn, take intelligent risks and shield them from unnecessary distractions. They should help them in doing the various little/big things that help them achieve small/big wins that make them have pride and dignity along the way. Some of the responsibilities a good supervisor should include expressing confidence, being decisive, giving credit where deserved, taking responsibility and even provide psychological counselling (Huntley \& Kleiner, 2014).

Magan (2018), in his conclusive remarks took note of the fact that local governance has been overvalued as an answer for development worldwide due to its positive attributes in development. In Africa, Local Governance, mobilization and distribution of wealth have been found to improve the relationship between citizens and the state, and also the quality of democracy. This view may be viable but the reality could be different in that many citizens are dissatisfied with the performance of Local Authorities in service delivery and get disengaged from local processes put in place to address local development. In Kenya, since independence the Government has been implementing local government reform programs with the view of enhancing service delivery and good performance but these efforts have met several challenges because of low management support from the entire system of management. 
Isaboke (2017), found that Kajiado county government had particular good results on the management support of the county activities, objectives and performance in terms of service delivery. It was observed that there was a positive relationship between organizational staff training and the organizational performance and concluded that leadership had significant effect on the performance of the county Government. Employees were found to be better motivated to work better and be more productive through good support. The management teams can empower their followers through shared visions, trust and common values by inspiring their influence across various networks. The study further clarified that managers should be responsive to staff issues since responding to staff issues promptly shows that a manager cares and this endears workers to stay longer in the organization.

Bourne (2015) observed that ineffective coordination of implementation of activities was one of the causes of failure like in scenarios where senior management sometimes by passes middle management and directly obtain information from and gives orders to the lower level employees. This causes ineffective communication lines in the implementing teams and severely compromises service delivery.

\section{Gaps in Existing Literature}

There is extensive literature on research that has been done and documented on how the devolved service delivery affect county governments. It has been shown that Management support has been identified to have positive effects on devolved systems which subsequently impact affirmatively the county government performance. The national government has developed Economic recovery strategy through introduction of performance contracting with the aim of strengthening performance for all government entities. It is therefore important to have employees with the right skills and management support for effective service delivery (Sinng, 2012).

Successful direction by management promotes team spirit, installs the mechanisms to develop team skills and defines team roles. Studies have clearly shown how county leadership and workforce impacts the quality of service delivery (Yaffe, 2012). The scholars in this review have called for county leaders to take charge of the team that they lead by making it safe for them to work, take intelligent risks, shielding them from unnecessary distractions that help them achieve one small win after the other and feel pride and dignity along the way. Expressing confidence and providing psychological safety are some of the responsibilities a good supervisor should take up (Huntley \& Kleiner, 2014). In a study done by Magan (2018), working with Dubai government showed that manager's performance of integrated leadership in government has a significant effect on employee 
happiness, as measured through job satisfaction and selfperceived performance.

In many studies in the literature, some vital aspects of multiple determinants of devolved service delivery have been left out that are addressed in this study. While Nyaga (2017) for example focused mainly on challenges of service delivery while the present study is focused on various un explored and most critical characteristics of service delivery in the counties in terms of management support, financial resources, strategic planning, stakeholder engagement and legal framework. These features have had scanty presence in the various available literature and therefore this study addresses the very vital gaps that exist and more or so provides the possible answers on the core determinants of the service delivery at the various county governments of Kenya.

\section{Methodology}

Correlational research design was used in this study that utilized mixed techniques approach. Pragmatic research philosophy was used as indicated in the objectives that guided the study to address the research questions under study in dealing with determinants of delivery of devolved service delivery in selected counties of Kenya. The study targeted 35,444 staff from 8 counties that were reachable based on land portrayal. The populace focused on are the official representatives for the administrative working with eight areas in Kenya, Nairobi, Mombasa, Nakuru, Embu, Kisumu, Nyeri, Kakamega and Garissa. Using Cochran equation the study sample size was 384. The study used Cluster and random sampling method to select the sample size. Data was collected using close and open ended questionnaires which incorporated Likert scale going from 1-5 where every respondent was required to rate every single proclamation given depicting a given variable. All the items in the variables were noted to be above the minimum 0.7 which is an acceptable rating on the Cronbach's alpha.

The Data collected was analysed using both the descriptive and the inferential statistics. Quantitative methods of data analysis was employed with both descriptive and inferential statistics was applied to explain each objective of the study. The descriptive statistics was preferred because it aided the study to meaningfully describe the population of study and was used to compute data frequency, percentage, percentage mean and STD deviation results aided by Statistical Packages for Social Science (SPSS). The analysed data was presented using frequency tables, bar graphs and pie charts using percentages and measure of central tendency that used to analyse data (Kothari 2006). The advantages of using frequency tables and bar graphs and chart is that frequency tables and bar graphs and charts present data in multiple categories and helps to summarize a large amount of data in a visual, easily interpretable 
form, (Crossman, 2013). Linear Regression model was also employed to establish the significance of the linear relationship of the independent the dependent variables. The linear regression model used was represented as; The simple regression model was;

$Y=\beta_{0}+\beta_{1} X+\varepsilon$

Where:

Y=Devolved services delivery

$\mathrm{X}=$ Management Support

$\varepsilon=$ Error term

$\beta_{0}=$ Constant $(\mathrm{Y}$ intercept $)$

$\beta_{1}=$ Is the regression coefficient of $X$

\section{Results}

384 questionnaire sets were distributed to the respondents and 363 questionnaires retrieved thus giving a response rate of $94.5 \%$. Of the 363 collected questionnaires only 346 were found to be useful for further analysis because further 17 questionnaires were excluded from the analysis due to outlier problem giving eventual $90.1 \%$ valid response rate. According to Sekaran and Bougie (2010), a response rate of $30 \%$ is acceptable for surveys. The response rate of this study is adequate for further analysis given that in this research, semi-structured questionnaires were used as instruments of collecting data, it was worth testing for its reliability. Rovai et al., (2014) recommended Cronbach's alpha as model that is adequate to measure internal consistency reliability based on the average inter-item correlation of an instrument. Thus, in the current study, Cronbach alpha was used. The results of reliability of research instrument are presented in the table below. According to Sekeran and Bougie (2010), the conventionally accepted level of reliability measure is set at 0.70 . From the results generated, the Cronbach alpha for each variable based on the average of inter-item correlation were above 0.70 with the highest Cronbach alpha value observed in Management Support (0.726) whereas 0.720 with respect to delivery of devolved services.

Therefore, any Cronbach alpha value more than 0.70 is regarded as a reliable measure that is Evident in the present study as seen results demonstrate that all variables had Cronbach alpha of more than 0.70 . Thus, met the required threshold for further analysis as presented in Table .1. 
Table 1: Reliability Results

\begin{tabular}{lccc}
\hline & Reliability Statistics & & \\
\hline & $\begin{array}{c}\text { Cronbach's } \\
\text { Alpha }\end{array}$ & $\begin{array}{c}\text { Cronbach's Alpha Based on } \\
\text { Standardized Items }\end{array}$ & $\begin{array}{c}\text { N of } \\
\text { Items }\end{array}$ \\
\hline Delivery of devolved & & & \\
services & 0.720 & 0.724 & 9 \\
Management support & 0.726 & 0.728 & 10 \\
\hline
\end{tabular}

\section{Descriptive Results}

Management support is without doubt critical in the provision of an enabling environment for effective devolved service delivery. It is a precondition for both effective and quality service delivery. The findings on top management support are illustrated in table 2. Evidence from the table suggests that the top management attends project meetings in various departments of the county (mean $=3.73, \mathrm{SD}=1.19$ ). In so doing, the top management is aware of the state of affairs at the county and are therefore likely to make decisions that are in tally with the county requirements.

Other than attending project meetings, the management provides for financial resources and organizational resources for the county services (mean $=3.60, \mathrm{SD}=1.07$ ). The implication is that the management facilitates service delivery at the county level, ensuring that financial resources are provided as the county top management provides leadership support and supervision to the county during projects implementation (mean $=3.62, \mathrm{SD}=1.05$ ). In fact, the county government leadership involve themselves in the implementation of the county projects (mean $=3.64, \mathrm{SD}=1.05$ ). This ensures that there is likelihood of projects being implemented to conclusion with reduced instances of source mismanagement.

Further, the county management review plans and the implementation of the projects (mean $=3.58, \mathrm{SD}=1.07)$. The management therefore ensure that the county attains its set objectives. However, it has not been fully established if the top county government officials take forms such as demonstrating commitment and also providing ways to overcome obstacles (mean $=3.37, \mathrm{SD}=1.03$ ). Similarly, there is doubt if there is a consistent communication between the implementation of county services and the top management of the county (mean $=3.34, \mathrm{SD}=1.15$ ). This could be deterrent to the attainment of efficient service delivery at the county government. 
Table 2: Management Support

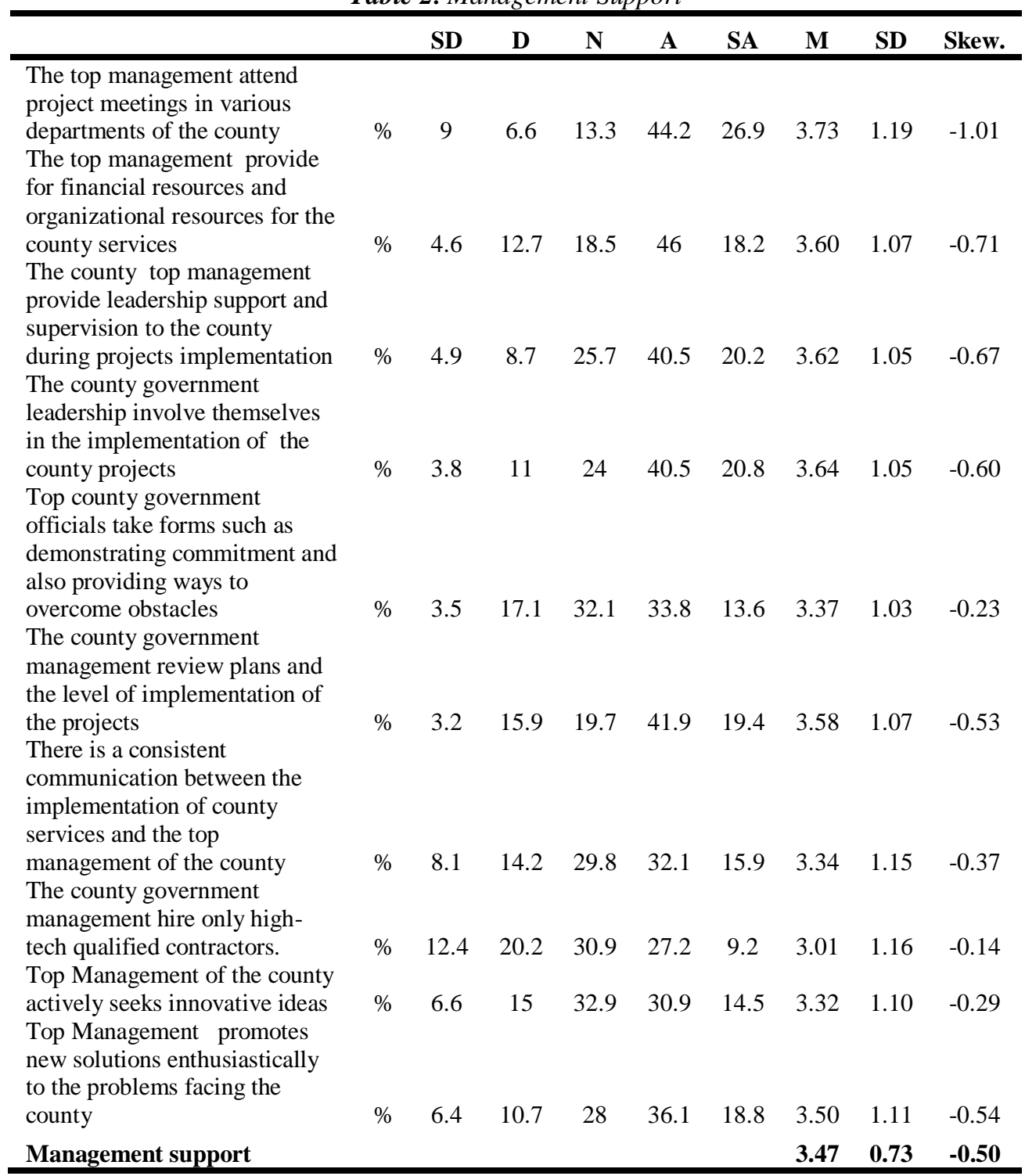

Besides, there are gaps with the hiring of only high-tech qualified contractors (mean $=3.01, \mathrm{SD}=1.16$ ). As well, it is undefined if the top management of the county actively seeks innovative ideas (mean $=3.32$, SD $=1.10$ ). These areas provide potential areas of improvement gaps because the top management need to be actively involved in the search for innovative ideas to solve public problems. This can be through the hiring of highly qualified contractors which has not been evidenced among the selected counties. On the flip-side, the top management promotes new solutions enthusiastically to the problems facing the county $($ mean $=3.5, \mathrm{SD}=1.11)$. 
In a nutshell, management support had a mean of 3.47, standard deviation of 0.73 and with skewness of -0.5 . Overall, the respondents were in agreement with the items on management support. The implication is that management support is a crucial step towards improved service delivery. Consistent with these findings, Isabokei (2017) argued that leadership has an influence on the performance of Kajiado County government particularly, through good management support. The employees are motivated to be more productive and work towards attaining the county's vision and mission. As well, Marks and Prints (2013) identified poor management as a major reason for low morale and unsatisfactory employee performance.

\section{Devolved Service Delivery}

In this section of the analysis, the results on devolved service delivery are presented. Basing on the findings in table 3, there is general improvements of services after establishment of county governments in Kenya (mean $=3.75$, $\mathrm{SD}=1.24$ ). Devolution has brought the government close to the people hence facilitating revenue generation. Nonetheless, it is not clear if the procurement of goods and services has improved since the county government took over (mean $=3.13, \mathrm{SD}=1.14$ ). Similarly, it is undefined if revenue collection and accounting functions are more efficient since the county government took over (mean $=3.23, \mathrm{SD}=1.18)$. This gives ground for further studies to ascertain the status of revenue collection and accounting functions since the advent of the county government.

Further, the respondents are not sure if transport services are more efficient after the implementation of devolution (mean $=3.14, \mathrm{SD}=1.07)$. It could be that data is not available for before and after performance of transport services. Besides, there is doubt if trading services and licensing has significantly improved after the county government took over the functions (mean $=3.39, \mathrm{SD}=1.12$ ). Just as well, it is unclear if food security has improved since the devolved government was introduced (mean $=3.08, \mathrm{SD}=$ 1.16).

In addition, there is uncertainty if sewerage and solid waste management is more efficient because of the county government (mean = $3.17, \mathrm{SD}=1.24$ ). Similarly, it is undefined if health service delivery improved since the county government took over its management (mean $=3.31, \mathrm{SD}=$ 1.20). Finally, it is unclear if agricultural services are better off with the county in place $($ mean $=3.23, \mathrm{SD}=1.20)$. The findings on devolved service delivery had an aggregate mean of 3.27, standard deviation of 0.87 and a skewness of -0.38 . 
Table 3: Devolved Service Delivery

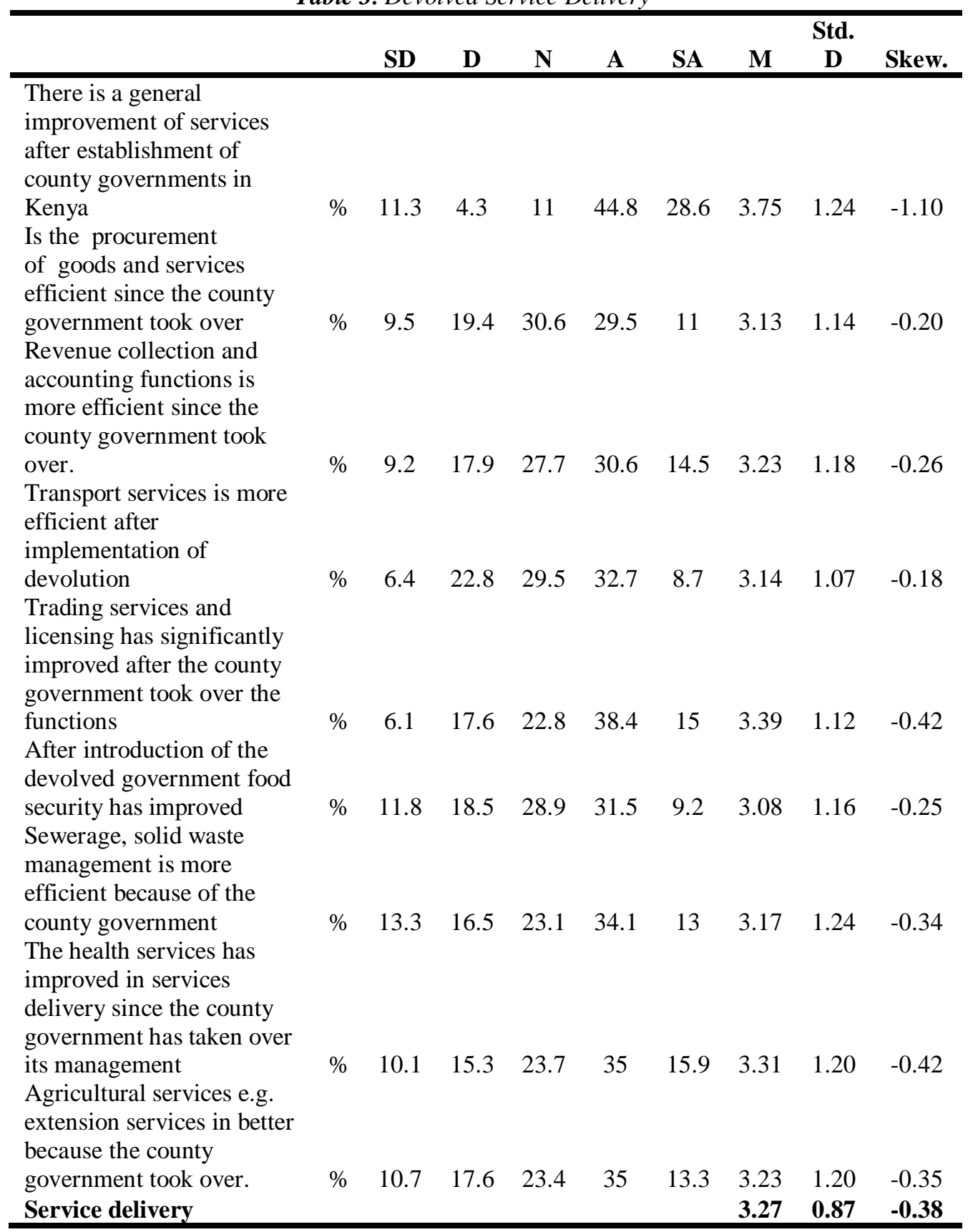

\section{Test of Hypothesis}

Through regression analysis, it is possible to systematically acknowledge the contribution of each independent variable and the predictive power of the model. 
$\mathbf{H}_{0}$ : Management support does not have a significant effect on the delivery of devolved services in selected counties in Kenya.

Hypothesis stated that management support do not have significant effect on the delivery of devolved services in selected counties in Kenya. Findings showed that management support had significant effect with $\beta$ value of 0.761 ( $\mathrm{p}$-value $=0.000$ which is less than $\alpha=0.05$ ). The null hypothesis was thus rejected and it was concluded that management support had a significant effect on devolved service delivery. This suggested that there was up to 0.761 unit increase in service delivery for each unit increase in management support. The effect of management support was 15 times the effect attributed to the error, this was indicated by the t-test value $=15.537$. Further, the findings in Table 4 indicated that $\mathrm{R}^{2}$ value $=0.412$ which shows that the model parameters account for $41.2 \%$ in the change of service delivery while the adjusted $\mathrm{R}^{2}=$ 0.411 indicates about $41 \%$. The analysis of variance attributed to the model parameters is significant as indicated by the F-ratio $=241.393$ with a $p$-value $=0.000$ which implies that the variation accounted for by the model parameters on service delivery was significant.

Table 4: Effect of Management support on the delivery of devolved services

\begin{tabular}{|c|c|c|c|c|c|}
\hline & \multicolumn{2}{|c|}{ Unstandardized Coefficients } & \multicolumn{3}{|c|}{ Standardized Coefficients } \\
\hline & B & Std. Error & Beta & $\mathbf{T}$ & Sig. \\
\hline (Constant) & 0.628 & 0.174 & & 3.616 & 0.000 \\
\hline Management support & 0.761 & 0.049 & 0.642 & 15.537 & 0.000 \\
\hline Summary Statistics & & & & & \\
\hline$R$ & 0.642 & & & & \\
\hline$R$ Square & 0.412 & & & & \\
\hline Adjusted R Square & 0.411 & & & & \\
\hline ANOVA (F stat) & 241.393 & & & & \\
\hline ANOVA (F prob) & 0.000 & & & & \\
\hline
\end{tabular}

a Dependent Variable: devolved service delivery

The findings from regression model showed that management support had positive and significant effect on the delivery of devolved services in selected counties in Kenya. The findings on management support indicated that the top management attends project meetings in various departments of the county and provides financial resources for the county services. Likewise, the county top management provides leadership support and supervision to the county during projects majorly during implementation.

Critical top management support includes broad range of activities in an organization, including developing project procedures with initiation stages, training programs, establishing project management offices with good supported quality management and so on. Young and Jordan (2008) suggest that "the essence of top management support related to effective decision- 
making to manage risk and to authorize business process change". Is a crucial part of a successful top management activity whose benefit of which is related to improving decision making without forgetting risk management. Top-level management responds to processes and manages county resources. Moreover, commitment and support from top management plays a key role in influencing the success in almost any initiative within any organization (Hasanali, 2002). Top management formulate and decides objectives and strategies for county activities, mission and overall objectives (Henriksen and Uhlenfeldt, 2006). The top management should provide solutions enthusiastically to the problems facing the county. However, it is unclear at times if the top county government officials demonstrate commitment in providing ways to overcome obstacles. In the same vein, there is doubt if there is a consistent communication between the implementation of county services and the top management of the counties. Besides, these gaps, is the question of hiring of only high-tech qualified contractors that makes it unclear whether the top management of the counties actively seek innovative ideas.

\section{Conclusion}

The study has enough evidence that management support provides an enabling environment at the county level that facilitates effective devolved service delivery. The top management are in a position of influence, provide supervision and ensure that financial resources are provided for at the county level. Besides, they are key in reviewing plans and the implementation of the projects. The top management are therefore at a focal point whereby they translate ideas into practices and it is through their support that counties are able to attain the much needed effective service delivery.

The management support is a good technique that can even be used for forecasting county activities, its variances on performance, the schedules and the costs of project activities. Besides, if the management provides adequate funds with good applicable operational practices to well-trained employees on project tools then the sky can be below par as a reasonable expected limit to attain.

\section{Recommendations}

Management support is instrumental in enhancing delivery of devolved services in selected counties in Kenya. It is a key factor in ensuring the sustainability of service delivery in county governments. It is therefore crucial that the management support systems are properly applied to support the county activities. The management also needs to ensure that adequate funds for county operations are provided together with adequate employee training on project tools in county projects to further facilitate quality delivery of devolved services. 
The county governments ought to provide not only for the financial and organizational resources for the county services but also for leadership support and supervision during project implementation. Most importantly, there is need for the top management to promote new solutions actively to the problems facing the county governments. Emphasis of the top management should be on actively seeking innovative ideas and providing solutions to problems before they even occur. They need to demonstrate commitment by signing job performance appraisal regularly and review plans at the various levels of implementation of the projects. The need for county government management to ensure consistent communication between the implementation of the various county services to employees cannot be over emphasized. Hiring of contractors need to be prioritized in the counties so as to actively seek innovative ideas and promote new solutions enthusiastically to the problems facing the county.

\section{References:}

1. Ayuso, S., Rodríguez, Á., García-Castro, R., \& Ángel Ariño, M. (2011). "Does stakeholder engagement promote sustainable innovation orientation. Industrial Management \& Data Systems, 111(9), 1399-1417.

2. Bigambo, J. (2013). Devolution in Kenya \& decentralization in Africa .Benchmarking. Inter thought consulting, connecting ideas beyond borders.

3. Bourne, A. (2015). The success and failure of performance measurement initiatives. International Journal of Operations \& Production Management, 22(11), 1288-1310.

4. Chebet, J. (2015). Determinants of Employees' Performance in the County Governments of Kenya; A Case of Bungoma County. University of Nairobi Repository.

5. Ekpo, A. H. (2008) Decentralization and Service delivery. A framework prepared for the African Economic Research Consortium (AERC), Nairobi, Kenya

6. Heathfield, S. (2018). Leadership Is the Key to Building Employee Support During Change. Executive leadershp change.

7. Huntley, J., \& Kleiner, B. (2014). Effective human resource management of county employees. Journal of Human resource management, 28(11/12), 60-68.

8. Isaboke, P. (2017). The Effects of Leadership Style Strategy on Performance of Kajiado County. International Journal of Contemporary Aspects in Strategic Management, 1(2), 39-49.

9. Juma, Rotich\&Mulongo,L.(2014).DevolutionandGovernanceConflictsinAfr 
ica: Kenyan Scenario. Public Policy and Administration Research 4 (6), 2224-5731.

10. Katee, E. (2013). Effect of Strategic Leadership on the Performance Of Commercial and Financial State Corporations In Kenya. Unpublished thesis of University of Nairobi.

11. Kauzya, J.M., 2007. Political Decentralization in Africa: Experiences of Uganda, Rwanda and South Africa. In: Cheema, G.S. \& Rondinelli, D.A., eds. 2007. Decentralizing Governance: Emerging Concepts and Practices. Washington: Brookings Institution Press.75-91.

12. Kothari, C. R. (2006). Research methodology: methods and techniques. New Delhi: Wiley and sons publishers.

13. Lodorfos, G.(2015). The Impact of Service Delivery System Effectiveness on Service Quality: A Hierarchical Approach 2015.School of Strategy, Marketing and Communication, Leeds Metropolitan University.

14. Lufunyo (2014). Decentralization and Human Resource Development; Documented Challenges in Local Government Authorities in Tanzania. International Journal of current research and academic review (3)6, 352-365

15. Magan, M. (2018). Exploring the link between integrated leadershipin-government and follower happiness: the case of Dubai. International Review of Administrative Science, 451-468.

16. Majekodunmi,A. (2012). The State of Local Government and Service Delivery in Nigeria: Challenges and Prospects. Africa's Public Service Delivery and Performance Review (1)84.

17. Marks, H., \& Printy, S. (2013). Principal leadership and school performance: An Integration of Transformational and Instructional Leadership. Educational Administration Quarterly, 39(3), 370-397.

18. Nyaga D. (2017). Challenges to service delivery in County governments: a case of Nyeri County. Strategic Journal of Business \& Change Management 4(3), 629 - 647,

19. Oloo, N. (2012). 2006. Devolution and Democratic Governance: Options for Kenya. Nairob. IPAR.

20. Olowu, D. (2008). Public Service Delivery in Public Administration in Africa. Main Issues and Selected Country Studies Adamolekun L. (ed). Safari Books, Channels Island. United Kingdom.

21. Olowu,D.\&Wunsch,J.S.(2004).LocalGovernanceinAfrica:TheChalle ngesof Democratic Decentralization,Boulder and London:LynneRienner

22. Omari, A,. O. Kaburi S. N. and Sewe. T. (2012) Change Dilemma: A Case Of Structural Adjustment Through Devolution In Kenya .International Journal of Arts and Commerce,1(7). 
23. Sarkar, A, E. (2003). The Illusion of Decentralization, Evidence from Bangladesh. International Journal of Public Sector Management, 16(7), 523-548.

24. Sharma, K(2010). Role of local government in Botswana for effective service delivery: Challenges, prospects and lessons. Commonwealth Journal of Local Governance 6.

25. Sinng, D. (2012). Building and Capacitating a Unified Public Administration and Management System for Integrated Service Delivery in South Africa. Public Personnel Management, 41(3), 420429.

26. UNDP. (2010). Innovations and Best Practices in Public Sector Reforms: The Case of Civil Service in Ghana, Economic Commission for Africa.

27. Wagana, D. \& Iravo, M. \& Nzulwa,J (2014). Analysis of the relationship between Devolved governance, political Decentralization, and service Delivery: a critical review of Literature. European Scientific Journal, 11(3), 1857 - 7881.

28. Woong, L., \& Yaccob, R. (2007). Stakeholders' Activisms: Indigenous Peoples' of Sarawak Resistance against the State Government and Corporations". Social Responsibility Journal, 3(2), 39-51.

29. Yaffe, J. (2012). Response to Occupational (Workforce) Literacy in a Large County Government Workforce. International Journal of Public Sector Management, 5(5). 